\title{
Corrigendum: Genome-wide association study of systemic sclerosis identifies CD247 as a new susceptibility locus
}

Timothy R D J Radstake, Olga Gorlova, Blanca Rueda, Jose-Ezequiel Martin, Behrooz Z Alizadeh, Rogelio Palomino-Morales, Marieke J Coenen, Madelon C Vonk, Alexandre E Voskuyl, Annemie J Schuerwegh, Jasper C Broen, Piet L C M van Riel, Ruben van 't Slot, Annet Italiaander, Roel A Ophoff, Gabriela Riemekasten, Nico Hunzelmann, Carmen P Simeon, Norberto Ortego-Centeno, Miguel A González-Gay, María F González-Escribano, Spanish Scleroderma Group, Paolo Airo, Jaap van Laar, Ariane Herrick, Jane Worthington, Roger Hesselstrand, Vanessa Smith, Filip de Keyser, Fredric Houssiau, Meng May Chee, Rajan Madhok, Paul Shiels, Rene Westhovens, Alexander Kreuter, Hans Kiener, Elfride de Baere, Torsten Witte, Leonid Padykov, Lars Klareskog, Lorenzo Beretta, Rafaella Scorza, Benedicte A Lie, Anna-Maria Hoffmann-Vold, Patricia Carreira, John Varga, Monique Hinchcliff, Peter K Gregersen, Annette T Lee, Jun Ying, Younghun Han, Shih-Feng Weng, Christopher I Amos, Fredrick M Wigley, Laura Hummers, J Lee Nelson, Sandeep K Agarwal, Shervin Assassi, Pravitt Gourh, Filemon K Tan, Bobby P C Koeleman, Frank C Arnett, Javier Martin \& Maureen D Mayes Nat. Genet. 42, 426-429 (2010); published online 11 April 2010; corrected after print 23 March 2011

In the version of this article initially published, incorrect affiliations were published for Lorenzo Beretta and Rafaella Scorza. The correct affiliation for Lorenzo Beretta and Rafaella Scorza is "Referral Center for Systemic Autoimmune Diseases, Fondazione IRCCS Ca' Granda Ospedale Maggiore Policlinico and University of Milan”. The error has been corrected in the HTML and PDF versions of the article.

\section{Corrigendum: TTC21B contributes both causal and modifying alleles across the ciliopathy spectrum}

Erica E Davis, Qi Zhang, Qin Liu, Bill H Diplas, Lisa M Davey, Jane Hartley, Corinne Stoetzel, Katarzyna Szymanska, Gokul Ramaswami, Clare V Logan, Donna M Muzny, Alice C Young, David A Wheeler, Pedro Cruz, Margaret Morgan, Lora R Lewis, Praveen Cherukuri, Baishali Maskeri, Nancy F Hansen, James C Mullikin, Robert W Blakesley, Gerard G Bouffard, NISC Comparative Sequencing Program, Gabor Gyapay, Susanne Rieger, Burkhard Tönshoff, Ilse Kern, Neveen A Soliman, Thomas J Neuhaus, Kathryn J Swoboda, Hulya Kayserili, Tomas E Gallagher, Richard A Lewis, Carsten Bergmann, Edgar A Otto, Sophie Saunier, Peter J Scambler, Philip L Beales, Joseph G Gleeson, Eamonn R Maher, Tania Attié-Bitach, Hélène Dollfus, Colin A Johnson, Eric D Green, Richard A Gibbs, Friedhelm Hildebrandt, Eric A Pierce \& Nicholas Katsanis

Nat. Genet. 43, 189-196 (2011); published online 23 January 2011; corrected after print 29 March 2011

In the version of this article initially published, the authors should have acknowledged that the work was also funded by a grant from the European Union (EU-SYSCILIA) to E.E.D., C.A.J., P.L.B. and N.K. The error has been corrected in the HTML and PDF versions of the article. 